\title{
FORMAÇÃO DOCENTE E O CUIDADO DE SI
}

Andreia Aparecida Cavalheiro ${ }^{1}$

\section{Introdução}

O objeto desta pesquisa é tratar da formação de professores e do cuidado de si neste processo. A expressão foucaultiana "cuidado de si”" busca, em um primeiro momento, incitar as pessoas a olharem para si mesmos e para seus processos formativos.

Sobre o objeto de pesquisa, os estudos de Minayo (2016) apresentam a seguinte abordagem:

O objeto das ciências sociais é histórico. Isto significa que cada sociedade humana existe e se constrói num determinado espaço e se organiza de forma particular e diferente de outras. Por sua vez, todas as que vivenciam a mesma época histórica têm alguns traços comuns, dado o fato de que vivemos num mundo marcado pelo influxo das comunicações. Igualmente, as sociedades vivem o presente marcado por seu passado e é com tais determinações que constroem seu futuro (MINAYO, 2016, p. 12-13).

Esse texto discute o objeto de estudo em Ciências Sociais como processo histórico, a diferença das formas de organização de cada sociedade e dos sujeitos nela envolvidos nos dias atuais. Nota-se que a realidade atual traz traços do passado, sendo que é por essa implicação que se vai construir o futuro.

Objetiva-se realizar uma leitura do cuidado de si nas concepções de Foucault e problematizar a formação docente a partir dessa abordagem. Desse modo, a problemática desse estudo é: como a formação de professores pode ser pensada a partir do cuidado de si?

O estudo se baseou inicialmente no estudo do curso da obra $A$ hermenêutica do sujeito (FOUCAULT, 2006) sobre o cuidado de si e em autores da área da formação docente: Tardif (2014), Imbernón (2010), entre outros.

Constata-se que a formação docente é uma preocupação que adentra historicamente diferentes sociedades. Mudam-se os contextos, a época e as exigências educacionais, mas de modo geral a necessidade de formar-se continua fruto de debates, discussões e problematizações no campo educacional.

\section{Materiais e métodos}

O estudo trata de uma pesquisa bibliográfica com abordagem qualitativa que busca elencar alguns pesquisadores da área da formação docente para responder à questão problema. Além disso, a investigação trabalha metodologicamente o campo da ética, a qual tem fundamento a partir dos estudos de Foucault.

A pesquisa qualitativa nas Ciências Sociais é capaz de responder questões particulares e estudar aspectos que englobam situações abstratas objetivadas na investigação (MINAYO, 2016).

Em relação à pesquisa bibliográfica, é fundamental salientar que essa trará conhecimentos necessários para a realização da investigação, tendo em vista que "[...] vamos buscar, nos

\footnotetext{
${ }^{1}$ Mestranda em Ensino (PPGEN-UTFPR-LD). Especialista em Ensino de Sociologia (UEPG, 2015). Professora do Colégio Vinícius de Moraes - SEED - Santa Amélia-PR. E-mail: andreiarouge26@ hotmail.com.
} 
autores e obras selecionadas, os dados para a produção do conhecimento pretendido[...]" (TOZONI-REIS, 2009, p. 35).

Em relação à investigação sobre o cuidado de si, o material selecionado consiste no estudo do curso de 1982 de Michael Foucault (2006) realizado no Collège de France, que resultou no livro A hermenêutica do sujeito. A obra é escrita a partir do diálogo de um conjunto de 12 aulas, subdivididas em duas partes: primeira hora e segunda hora de cada aula.

\section{Cuidado de si em Foucault}

Segundo Foucault (2006), Sócrates, na sociedade ateniense, era aquele que promovia o despertar, assumindo o papel de incitar as pessoas. Naquele contexto, ele se ocupava em tentar despertar em Alcibíades (aristocrata herdeiro do direito de governar a cidade) a necessidade de ocupar-se consigo, melhorando sua formação.

Foucault (2006, p. 11) aborda sobre o cuidado de si na seguinte perspectiva:

[...] situa-se exatamente no momento em que se abrem os olhos, em que se sai do sono e se alcança a luz primeira. [...] O cuidado de si é uma espécie de aguilhão que deve ser implantado na carne dos homens, cravado na sua existência, e constitui um princípio de movimento, um princípio de permanente inquietude no curso da existência.

A noção enfatizada no texto traz uma reflexão relevante, no sentido de relacionar o cuidado de si com a ideia de enxergar sob uma ótica mais apurada, além de comparar o cuidado de si com um aguilhão, algo que faz parte da condição humana e que incomoda e incita ao mesmo tempo.

A ideia de verdade traz outras questões fundamentais para a formação do sujeito quando o autor afirma que "[...] não pode haver verdade sem uma conversão ou sem uma transformação do sujeito [...]", sendo movido por um trabalho de si para consigo mesmo, responsável por um trabalho que leva a uma transformação do sujeito, sendo capaz de uma verdade (FOUCAULT, 2006, p. 20).

Segundo Foucault (2006), a história da verdade na Idade Moderna passa ser relacionada com o acesso ao conhecimento. Nesse sentido, algumas condições são impostas e estabelecidas para ter acesso a ela, sendo uma delas a necessidade de realizar estudos, de ter uma boa formação.

No entanto, aos poucos a noção de cuidado de si foi desaparecendo do pensamento filosófico, rompendo a relação entre a aquisição da verdade e do conhecimento. Nessa perspectiva foucaultiana, a verdade está relacionada à condição de formação dos sujeitos (FOUCAULT, 2006).

Outro fato interessante abordado no curso de 1982 por Foucault é a passagem de um período histórico que retrata a vida dos espartanos, quando Plutarco indaga um espartano sobre os motivos dos mesmos não cultivarem suas vastas terras, mas deixavam a tarefa aos cuidados de outros povos, no caso os hilotas. Nesse caso, o interessante é que a resposta está associada ao cuidado de si, a ter tempo: “[...] para podermos ocupar com nós mesmos [...]". Portanto, naquele momento, o cuidado de si era associado a um privilégio para aquele que podia cuidar de si (FOUCAULT, 2006, p. 42).

No curso ministrado por Foucault, em 1982, a ideia de formação retratada entre os séculos I e II na sociedade greco-romana aparece em primeiro momento como necessidade de preparar para ser um bom governante, podendo o sujeito formar-se não especificamente para uma profissão, mas para enfrentamentos de questões e problemas que poderiam surgir no decorrer da vida.

De fato, na perspectiva de Foucault (2006, p. 160), o curso de 1982 apresenta a questão formadora como preocupação relevante, em princípio na relação de mestre e aprendiz, sendo que o mestre atuaria de forma mediadora: “[...] mestre é um operador na reforma do indivíduo e na formação do indivíduo como sujeito. É mediador na relação do indivíduo com a constituição do sujeito [...]". 
No decorrer do estudo, pode-se verificar que desde a antiguidade grega é apresentada a ideia de "desaprendizagem", na medida que se acreditava que as pessoas viviam em contexto de falseamento e se encontravam no processo de assujeitamento desde a família até a escola, instituições que buscariam impor modelos ou modos de vida. Além disso, ocorre um processo de "conversão" a si mesmo, o qual possibilita compreender a ideia de desaprendizagem, quando esse movimento de conversão faz com que as pessoas busquem compreender a si mesmos e incita o olhar para si (FOUCAULT, 2006, p. 254-258).

Em suma, o cuidado de si em Foucault busca retratar a seu tempo, uma necessidade que surge entre os gregos, na antiguidade, de cuidar de si para cuidar do outro. Em um primeiro momento, essa visão associa-se à necessidade de governar a cidade e, depois, vai assumindo novos entendimentos, como a relação e acesso à verdade e a aquisição de conhecimentos, pois o cuidado de si passa também a ser pensado à luz da modernidade.

\section{Reflexões sobre o ensino e a formação de professores}

A formação de professores e, principalmente, a formação inicial, teve início desde a antiguidade, quando se passou a preocupar-se com o ensinar. Desse modo:

[...] desde o momento que alguém decidiu que outros educariam os seus filhos e esses outros tiveram que se preocupar em fazê-lo [...]. Entretanto, nesta prática de educar o outro, surgem diferentes inquietações para realizar a educação, como: [...] de que maneira, com quais conhecimentos (IMBERNÓN, 2010, p. 13).

Adentrando o campo educacional, pensar em ocupar-se consigo está relacionado aos saberes docentes e ao processo de formação do professor. Tardif $(2014$, p. 31) evidencia que "[...] parece banal, mas um professor é, antes de tudo, alguém que sabe alguma coisa [...]". No entanto, "[...] todo saber implica em um processo aprendizagem e formação [...]".

De modo geral, assim como a formação é uma preocupação da antiguidade, o ensino também o é, e mesmo assim há uma dificuldade em apontar os saberes envolvidos nesse processo. Assim são evidenciadas algumas ideias preestabelecidas que levam os erros que deixam o ensino numa espécie de "cegueira conceitual" (GAUTHIER et al, 2013, p. 20).

Por muito tempo as ideias pré-concebidas do ensino foram: apenas saber o conteúdo é suficiente para transmiti-los aos alunos; ter talento ou ter bom senso, seguir sua intuição, ter experiência e ter cultura é essencial no ensino. Essas ideias, para Gauthier et al, (2013, p. 25), "[...] prejudicam o processo de profissionalização do ensino, impedindo o desabrochar de um saber desse ofício sobre si mesmo $[\ldots]$ ”.

Verifica-se que essas ideias preestabelecidas de ensino podem comungar com o termo grego usado por Foucault (2006, p. 400), "ascese", que em um momento possibilita agregar o discurso verdadeiro e em outro, pode assumir função dos sujeitos serem responsáveis por estes mesmos discursos. Desse modo, a reprodução desses discursos, se conduzida da forma indiscriminada pelos sujeitos, pode fazer com que os indivíduos sejam persuadidos por verdades forjadas ao longo da história da educação.

Segundo Imbernón (2010), apesar dos avanços na trajetória da formação docente entre os séculos XX e XXI, ainda são necessárias mudanças. De acordo com o autor, atualmente parece haver um retrocesso no processo de formação continuada, uma vez que se verifica a tentativa de uma formação baseada em "[...]lições modelos, de noções oferecidas em cursos, de ortodoxia em ver e a realizar a formação, de curso padronizados, ministrados por especialistas - nos quais 
o professor é o ignorante que assiste as sessões que o 'culturalizam e iluminam' profissionalmente" (p. 8-9).

A constatação de Imbernón (2010) ressalta falhas no processo de formação continuada, o qual desconsidera o saber docente, deixando o professor como papel secundário em sua própria formação. Essa crítica concorda com Tardif (2014, p. 240), que afirma: “[...] reconhecer que os professores de profissão são sujeitos do conhecimento é reconhecer ao mesmo tempo que deveriam ter o direito de dizer algo a respeito de sua própria formação profissional [...]”.

Verifica-se que Tardif (2014) defende que o processo de formação docente implica em reconhecimento do professor como um sujeito que tem muito a dizer sobre sua formação, sendo que essa questão não pode ser desconsiderada no processo.

Eckert-Hoff (2008) compreende por formação docente um "processo múltiplo, não-linear, com uma pluralidade de vozes, de práticas de saberes, acumulados em todo percurso históricosocial-ideológico do sujeito [...]". A autora destaca que a formação de docente é um processo constituído por diversos sujeitos de conhecimento que foram sendo acumulados historicamente.

Segundo Gaurthier et al (2013, p. 17-25), o ensino existe em amplitude universal, atingindo diversas sociedades ao longo do tempo e exerce papel relevante na sociedade atual. No entanto, apesar do ensino abranger a maioria da sociedade, diversas problemáticas ainda precisam ser investigadas e superadas na tentativa de melhorar o ofício do professor.

Em relação ao ato de ensinar, Freire (1996, p. 47) traz um ponto de vista bastante relevante: "quando entro em uma sala de aula devo estar sendo um ser aberto a indagações; um ser crítico e inquirido, inquieto em face de tarefa que tenho - a de ensinar e não de transferir conhecimento". Dessa maneira, é ressaltado que ensinar requer do professor um trabalho que envolva as indagações na relação professor-aluno, de modo que quem ensina não pode ter papel de mero transmissor de conteúdo, pois deve levar em consideração as indagações dos alunos, contribuindo para a construção do pensamento crítico.

Quanto à formação do professor, Nóvoa (1992) deixa claro que esse processo deve despertar ação crítico-reflexiva, no sentido de que o professor faça um investimento pessoal, não sob acúmulos de cursos, mas que ocorra uma reflexão do trabalho realizado a partir da prática, valorizando, assim, suas experiências com o ensino.

Verifica-se que, assim como Nóvoa (1992), Pimenta (1997) salienta que a formação de professores na perspectiva reflexiva significa valorizar a prática do professor, o trabalho que realiza, suas experiências compartilhadas, havendo uma relação entre os saberes escolares do professor e a formação realizada pela sua escola de atuação.

Tardif (2014) retrata ainda algumas dificuldades enfrentadas pelos professores nos primeiros anos de profissão docente. $\mathrm{O}$ autor diz que os professores iniciam a carreira docente atuando por experimentação e, muitas vezes, chegam a ficar frustrados pela busca de segurança no ato de ensinar ou pela própria aceitação no ambiente escolar. Além disso, muitos professores se encontram na precariedade de atuação, pois a falta de estabilidade os faz atuar a cada momento em escolas e turmas diferentes, tendo que recomeçar o trabalho a cada momento.

Segundo Pimenta (1997), nas atividades de estágios, a formação inicial de professores configura-se como um processo baseado meramente na burocracia, não contribuindo para a percepção das realidades contraditórias. Quanto à formação continuada, não colocam a prática do professor como ponto a ser atingido na formação. Para Libânio (2010), devido à transformação globalizante que vem sofrendo a sociedade nos últimos anos tem sido estabelecida a necessidade de uma formação de professores com novas exigências educacionais. O objetivo é que o ensino seja tomado de forma mediadora, propiciando uma aprendizagem ativa dos alunos, ou seja, o ensino verbalista e meramente transmissor de conhecimento precisa ser revisto. 
Para Veiga Neto (2011), o surgimento da escola como espaço de educação a ser considerada na modernidade traz uma série de verdades, o que faz com que esses locais se tornem um locus moralizante. Entende-se, assim, que um dos maiores desafios da formação de professores consiste em "[...] examinar o que funciona, o que deve ser abandonado, desaprendido, construído de novo ou reconstruído a partir daquilo que é velho" (IMBERNÓN 2010, p. 27).

Enfim, os estudos levam a constatar que o processo de formação de professores é um processo antigo; que no passado teve contextos e inquietações diferentes dos dias atuais, não sendo, assim, um processo linear. Porém, são os vestígios deixados pelas sociedades antigas que possibilitaram muitas problematizações e analogias entre a educação moderna e atual. Portanto, na investigação, fica evidente a possibilidade de problematização do cuidado de si como instrumento para repensar a formação docente, convertendo o olhar para si e para o processo de formação do professor.

\section{Considerações finais}

O estudo realizado confirma que o processo de formação é tão antigo quanto a necessidade do ensino, uma vez que a partir do momento em que surge o ensino, aparece também a dúvida de como ensinar. Assim, a formação passa ser uma necessidade que tem sido repensada em diferentes momentos.

Muitos discursos e teorias envolvem o processo de formação de docentes, sendo necessário desaprender muitos discursos que o cercam, principalmente a ideia de que o professor nada sabe e que são pessoas alheias a sua realidade que devem dizer o que fazer.

Desse modo, os estudos de Foucault (2006) sobre o cuidado de si sobre povos gregosromanos na Antiguidade, assim como na transição para a Idade Moderna dizem muito sobre a necessidade de formação dos sujeitos. Primeiramente, na associação ao bom governo; depois, numa perspectiva das escolas filosóficas, na formação do filósofo; e, por fim, na constituição do sujeito e na relação entre verdade e conhecimento.

Dessa maneira, na tentativa de promover o cuidado de si, Foucault (2006) traz à tona a ideia de conversão, uma conversão de si mesmo, buscando retornar a si mesmo. Tal conversão pode ser um processo relevante se pensar esse retorno de si como uma dinâmica da formação do professor, constatando lacunas, fragilidades da formação, a fim de o sujeito entendê-las para poder ocupar-se consigo mesmo.

No entanto, esse processo de conversão relacionado à necessidade de formação do professor não quer estigmatizar o professor como o ignorante, mas tem a intenção de despertálo para a necessidade de formar-se, seja em fase inicial ou continuada. As inquietações que envolvem o processo de ensino-aprendizagem, bem como os discursos que circulam na escola como espaço de ensino, precisam ser repensadas e analisadas pelo professor constantemente, a fim de que ele não seja o responsável por professar verdades inquestionáveis na escola.

Em suma, o estudo possibilitou compreender a necessidade do cuidado de si no processo de formação de docente. Esse cuidado de si na abordagem de Foucault incita cada qual a olhar para seu percurso de formação, analisando quais os pontos positivos e negativos desse processo que precisam ser descontruídos e reconstruídos, a fim de ocupar-se consigo mesmo e construirse a partir de uma formação que não seja mais espaço de verdades absolutas.

\section{Referências}

ECKERT-HOFF. B. M. Escritura de si e identidade: o sujeito - professor em formação. Campinas: Mercado das Letras, 2008. 
FREIRE, P. Pedagogia da autonomia: saberes necessários à prática educativa. 42. ed. São Paulo: Paz e Terra, 1996.

FOUCAULT, M. A hermenêutica do sujeito: curso do Collège de France (1981-1982). Tradução de M. A. Fonseca e S. T. Muchail. 2. ed. São Paulo: Martins Fontes, 2006.

GAUTHIER, C et al. Por uma teoria da pedagogia: pesquisas contemporâneas sobre o saber docente. Tradução de F. Pereira. $3^{\text {a }}$ ed. Rio Grande do Sul: Unijui, 2013.

IMBERNÓN, F. Formação continuada de docentes. Tradução de J. S. Padilha, Porto Alegre: Artmed, 2010.

MINAYO, M. C. S. O desafio da pesquisa social. In: MINAYO M. C. S; DESLANDES, S. F; GOMES, R. (Org.). Pesquisa social: teoria, método e criatividade. Petrópolis: Vozes, 2016.

NÓVOA, A. Formação de professores e profissão docente. In: NÓVOA, A. Os professores e a sua formação. Lisboa: Dom Quixote, 1992. Disponível em: <http://hdl.handle.net/10451/4758>. Acesso em: 10 ago. 2018.

PIMENTA, S. G. Formação de professores: saberes da docência e identidade do professor. Nuances, $\quad$ v. $\quad$ III, $\quad$ set. $1997 . \quad$ Disponível em: <http://revista.fct.unesp.br/index.php/Nuances/article/download/50/46>. Acesso em: 10 ago. 2018.

LIBÂNEO, J. C. Adeus professor, adeus professora: novas exigências educacionais e profissão docente. 12. ed. São Paulo: Cortez, 2010.

TARDIF, M. Saberes docentes e formação profissional. 17. ed. Petrópolis: Vozes, 2014.

TOZONI-REIS, M. F. C. Metodologia da pesquisa. 2. ed. Curitiba: IESDE Brasil AS, 2009.

VEIGA-NETO, A. Foucault e a educação. 3. ed. Belo Horizonte: Autêntica. 2011. 